\title{
Factors affecting malnutrition in children and the uptake of interventions to prevent the condition
}

\author{
Edem M. A. Tette ${ }^{1,2^{*}}$, Eric K. Sifah ${ }^{2}$ and Edmund T. Nartey ${ }^{3}$
}

\begin{abstract}
Background: Malnutrition is a major cause of child morbidity and mortality. There are several interventions to prevent the condition but it is unclear how well they are taken up by both malnourished and well nourished children and their mothers and the extent to which this is influenced by socio-economic factors. We examined socio-economic factors, health outcomes and the uptake of interventions to prevent malnutrition by mothers of malnourished and well-nourished in under-fives attending Princess Marie Louise Children's Hospital (PML).
\end{abstract}

Methods: An unmatched case control study of malnourished and well-nourished children and their mothers was conducted at PML, the largest facility for managing malnutrition in Ghanaian children. Malnourished children with moderate and severe acute malnutrition were recruited and compared with a group of well-nourished children attending the hospital. Weight-for-height was used to classify nutritional status. Record forms and a semi-structured questionnaire were used for data collection, which was analysed with Stata 11.0 software.

Results: In all, 182 malnourished and 189 well-nourished children and their mothers/carers participated in the study. Children aged 6-12 months old formed more than half of the malnourished children. The socio-demographic factors associated with malnutrition in the multivariate analysis were age $\leq 24$ months and a monthly family income of $\leq 200 \mathrm{GH}$ Cedis. Whereas among the health outcomes, low birth weight, an episode of diarrhoea and the presence of developmental delay were associated with malnutrition. Among the interventions, inadequate antenatal visits, faltering growth and not de-worming one's child were associated with malnutrition in the multivariate analysis. Immunisation and Vitamin A supplementation were not associated with malnutrition. Missed opportunities for intervention were encountered.

Conclusion: Poverty remains an important underlying cause of malnutrition in children attending Princess Marie Louise Children's Hospital. Specific and targeted interventions are needed to address this and must include efforts to prevent low birthweight and diarrhoea, and reduce health inequalities. Regular antenatal clinic attendance, de-worming of children and growth monitoring should also be encouraged. However, further studies are needed on the timing and use of information on growth faltering to prevent severe forms of malnutrition.

Keywords: Malnutrition, Children, Prevention, Diarrhoea, Risk factors, Interventions

\footnotetext{
* Correspondence: edemenator@googlemail.com

'Department of Community Health, School of Public Health, University of

Ghana, P.O. Box 4236, Accra, Ghana

${ }^{2}$ Princess Marie Louis Children's Hospital (PML), P.O. Box GP 122, Accra,

Ghana

Full list of author information is available at the end of the article
}

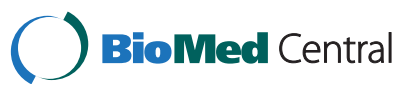

(C) 2015 Tette et al. Open Access This article is distributed under the terms of the Creative Commons Attribution 4.0 International License (http://creativecommons.org/licenses/by/4.0/), which permits unrestricted use, distribution, and reproduction in any medium, provided you give appropriate credit to the original author(s) and the source, provide a link to the Creative Commons license, and indicate if changes were made. The Creative Commons Public Domain Dedication waiver (http://creativecommons.org/publicdomain/zero/1.0/) applies to the data made available in this article, unless otherwise stated. 


\section{Background}

Malnutrition is regarded as the most important risk factor for illness and death globally and it is associated with $52.5 \%$ of all deaths in young children [1-4]. According to UNICEF, WHO and the World Bank, out of the 161 million under-fives estimated to be stunted globally in 2013, over a third resided in Africa [5]. In addition, about one-third of the 51 million under-fives who were wasted and the 99 million who were underweight were also from Africa [5]. Furthermore, although there has been a global decline in underweight from $25 \%$ to $15 \%$, Africa has experienced the smallest relative decrease in prevalence going from $23 \%$ in 1990 to $17 \%$ by 2013 [5].

In children, low birth weight, feeding problems, diarrhoea, recurrent illness, measles, pertussis, and chronic disease among others increase the risk of malnutrition [6-8]. These factors vary from locality to locality and children under five years are most at risk. Social factors also have an influence on malnutrition and in the 1990's, malnutrition was associated with young mothers and low maternal socio-economic status at Princess Marie Louise Children's Hospital (PML) [6].

The consequences of malnutrition are many and have been extensively documented [2-4, 8, 9]. It includes increased risk of infection, death, and delayed cognitive development, leading to low adult incomes, poor economic growth and intergenerational transmission of poverty [9]. Children with malnutrition have reduced ability to fight infection and are more likely to die from common diseases such as malaria, respiratory infections and diarrhoeal diseases $[2-4,8]$. Children who are born with low birth weight and have intrauterine growth retardation, are at increased risk of morbidity and mortality, and other forms of malnutrition compared to healthy infants. They also tend to develop non-communicable diseases such as diabetes and hypertension in adult life [10]. Interventions for reducing malnutrition must therefore begin before birth.

Reproductive Health Services provide the settings for political strategies that can reduce low birth weight by enhancing birth spacing and reducing teenage pregnancy [11-13]. Maternal malnutrition, low gestational weight gain, weight loss due to illness, medical conditions during pregnancy such as malaria, hypertension, smoking, drug and alcohol use, increase the risk of low birth weight [10]. Antenatal care provides the setting to identify and treat such high-risk pregnancies and it offers nutritional and educational interventions which can promote healthy eating habits, hygienic practices and lifestyle changes to reduce low birth weight [10]. Thus low birth weight can be a measure of success in preventing malnutrition during pregnancy through antenatal care.

Promotion of breastfeeding, appropriate complementary feeding, vitamin A supplementation and case management of malnutrition are most effective at preventing malnutrition or its effects $[11,14]$. De-worming programmes and conditional cash transfer have been reported to be effective only in specific situational context, while there is little evidence for the effectiveness of interventions such as growth monitoring. Intervention such as immunization and education on clean hygienic practices and nutritional counselling at post-natal and child welfare clinics can also prevent malnutrition [15].

Repeated attacks of diarrhoea and infections leads to weight loss and compromise a child's nutritional status $[1,15]$. This in turn makes the child vulnerable to infections and further weight loss, eventually leading to severe malnutrition unless the cycle is broken. Thus recurrent diarrhoea and sickness episodes reflect the effectiveness of health interventions to prevent and manage diarrhea and infections, and hence prevent malnutrition.

Ghana has several policies and programmes to reduce malnutrition [16, 17]. This includes reproductive health interventions such as antenatal and postnatal care and interventions contained in the Under Fives Child Health Programme. The latter includes promotion of breast feeding, appropriate complementary feeding, growth monitoring, Vitamin A supplementation and immunisation. Others are regular de-worming and strategies for feeding children with special nutritional requirements such as infants of mothers with HIV infection or AIDS [17]. The programme also provides information on appropriate treatment of childhood illnesses such as diarrhoeal diseases [11, 14, 17].

In recent times there has been renewed interest in preventing malnutrition however there is insufficient data on the uptake of these health interventions and the factors which affect them. According to UNICEF the main causes of childhood malnutrition can be categorized into three main underlying factors which are; household food insecurity, inadequate care and unhealthy household environment, and lack of health care services [18]. These in turn are affected by income, poverty, employment, dwelling, assets, remittances, pensions and transfers which are also determined by socio-economic and political factors.

Interventions to prevent malnutrition must target these underlying causes. Thus we examined social factors, health outcomes and the uptake of interventions to prevent malnutrition by mothers of malnourished and well-nourished children under the age of five years attending PML.

\section{Methods}

\section{Study design}

An unmatched case-control study was conducted at the Princess Marie Louise Children's Hospital in Accra. Cases were defined as children under the age of 5 years with either Moderate Acute Malnutrition (MAM- a weight for height $Z$ score of $\geq-3 S D$ to $<-2 \mathrm{SD}$ ) or Severe Acute Malnutrition (SAM-a weight for height $\mathrm{Z}$ score of $<-3 \mathrm{SD}$ 
with or without bilateral pitting oedema). The controls were children under the age of 5 years with wellnourished nutritional status (a weight for height $\mathrm{Z}$ scores $>-2 \mathrm{SD}$ ). The study was part of a larger study which also examined feeding practices, maternal, social, medical and biologic factors associated with malnutrition. We present here the extent of exposure of these children and their mothers to selected health interventions that prevent the malnutrition and the sociodemographic and health outcomes affecting them.

\section{Study setting}

Princess Marie Louise Children's Hospital is the largest centre dedicated to treating children with malnutrition in the country. The hospital is a 74 bed children's hospital situated in the commercial centre of the capital, Accra. It provides both primary care and specialized paediatric services for patients brought in by their parents and referrals from health facilities in other parts of Accra and from other regions. In 2012, there were 157 admissions for MAM and SAM at PML with a mortality rate of $11.7 \%$ as reported by the Dietetic unit. The WHO protocol informs case management at the hospital.

\section{Study population}

Patients with malnutrition were identified initially by measuring the Mid Upper Arm Circumference (MUAC) as this is the main measurement used for admitting and identifying patients with SAM and MAM in Ghanaian nutritional rehabilitation centres. Those with Severe Acute malnutrition (SAM), a weight for height Z score of $<-3 \mathrm{SD}$ with or without bilateral pitting oedema (WHO) and Moderate Acute Malnutrition (MAM), a weight for height $\mathrm{Z}$ score of $\geq-3 \mathrm{SD}$ to $<-2$ SD (WHO) were included as cases $[19,20]$. Patients with a weight for height $\mathrm{Z}$ scores $>-2 \mathrm{SD}$ presenting with other conditions were included as controls.

Children who met MUAC criteria but did not meet weight for height criteria or had missing weight or height measurements were excluded from the study. Children with chronic diseases which have an influence on nutritional status, including congenital heart disease, renal failure, sickle cell disease or liver disease and their mothers were also excluded from both study groups. Also excluded were children who had been in the nutritional rehabilitation programme for more than 7 days and their mothers. Children who were severely ill were also excluded until they were stable, if this was within the 7 days.

\section{Sampling}

Purposive sampling was used in this study. We recruited consecutive patients with MAM and SAM admitted to the malnutrition ward or referred to the nutritional rehabilitation unit into the study between $9^{\text {th }}$ January and $10^{\text {th }}$ June 2013 who met weight-for height and other inclusion criteria, and gave consent. A comparative group of children attending PML who were being seen or treated for conditions other than malnutrition were recruited from the out-patients department and from the general paediatric wards if they had a weight-forheight $\mathrm{z}$ score of $<-2 \mathrm{SD}$, met inclusion criteria and gave consent. These were classified as controls but were not matched by age or sex to the cases.

We had some challenges recruiting controls especially from the general wards as many of those screened did not meet the criteria for being "well nourished". Thus we extended the time of recruitment of the comparison group to $10^{\text {th }}$ September 2013 due to difficulty obtaining suitable controls and because of an industrial action which reduced patient attendance.

\section{Measurements and data collection}

A Class III infant scale (Seca 334) was used to measure the children's weight. A Seca 417 measuring board was used to measure length while height measurements were done using a Leicester height measure. These were recorded to the nearest millimetre. MUAC and head circumference were done using non-stretch tape measures. Research personnel making these measurements were trained in standardized techniques for performing these measurements. A Royal College of Paediatrics and Child Health training video clip was used as part of the training.

Weight-for-height measures wasting or acute malnutrition and can be expressed as a z-score which is the number of standard deviations or Z-scores below or above the reference mean or median value [21]. The Mid-Upper Arm Circumference (MUAC) is the arm circumference taken at the midpoint between the tip of the shoulder (acromium process) and the tip of the elbow (olecranon process). Both measurements measure wasting or acute malnutrition but correlation between them is often poor. MUAC is better predictor of mortality, easier and less cumbersome to perform and therefore is recommended for use in community-based screening [22].

A semi-structured questionnaire and a data record form were used to collect the information on the child's profile. The information collected included data on the child's age, sex, birth weight and birth order, maturity and problems at birth, child development, HIV status, chronic illness, illness episodes and diarrhoeal episodes over the past year. Information on nutritional status, sources of nutrition advice, growth pattern, immunisation status and preventive interventions such as deworming, vitamin A supplementation and antenatal and postnatal visits was also obtained.

Information on faltering growth was obtained from the Child Health Record and in this study it was defined 
as a fall off the growth curve through two or more centile spaces on the growth chart. At the time, adequacy of antenatal visits was defined as 4 or more antenatal visits and postnatal visits as two or more postnatal visits.

\section{Statistical analysis}

The data were entered into a Microsoft Access (Microsoft Corporation, Redmond, Washington) and analysed using Stata $11.0^{\circ}$ (College Station, Texas 77845 USA). Classification of malnutrition using weight for length/ height measurements was done using the WHO Anthro for personal computers, version 3.2.2, 2011. Frequencies and means were computed. The results were presented using tables, graphs with statistical inference. Both univariate and multivariate analysis were done to determine factors associated with malnutrition with the variables grouped under socio-economic and demographic factors, health outcomes and uptake of interventions. Variables significant at $p<0.2$ in the univariate analysis were entered into the final multivariate analysis model. Statistical significance was accepted at a $5 \%$ probability level, i.e. a $p$-value of less than 0.05 .

\section{Ethics}

Ethical approval was sought and obtained from the University of Ghana Medical School's Ethical and Protocol Review Committee [Protocol Identification Number: MS-Et/M.8-P.5.8/2011-2012]. Ethical approval was also obtained from the Ghana Health Service Ethical Review Committee [Protocol Identification Number GHS-ERC 05/07/2012]. Written consent was obtained from the mothers/guardians of the children using consent forms which were signed or thumb printed.

\section{Results}

\section{Description of the study participants}

Table 1 shows the socio-economic and demographic description of the study participants. A total of 371 children participated in the study involving $182 \mathrm{mal}-$ nourished children and 189 well-nourished children and their mothers. Female children constituted $52.7 \%$ $(n=96)$ and $47.6 \%(n=90)$ of the malnourished and well-nourished groups respectively. More than half of the malnourished children were in the 6 months to 12 months age group with a median age of 11 months in the malnourished group. Or over $40 \%$ of both groups were aged between 12 and 24 months. A total $86.0 \%(n=154)$ of mothers of malnourished children were educated and $93.5 \%(n=174)$ of mothers of wellnourished children were also educated. An assessment of the occupational status indicated that $18.1 \%(n=33)$ and $7.9 \%(n=15)$ of mothers of malnourished children and well-nourished children respectively were unemployed.
Table 1 Socio-economic and demographic characteristics of 371 children and their mother's (caregivers) attending PML hospital in Accra, Ghana

\begin{tabular}{|c|c|c|c|}
\hline \multicolumn{2}{|l|}{ Characteristic } & \multicolumn{2}{|c|}{ Nutritional status of child } \\
\hline Gender & & $\begin{array}{l}\text { Malnourished } \\
n, \%\end{array}$ & $\begin{array}{l}\text { Well-nourished } \\
n, \%\end{array}$ \\
\hline & Female & $96(52.7)$ & $90(47.6)$ \\
\hline & Male & $86(47.3)$ & $99(52.4)$ \\
\hline \multicolumn{4}{|l|}{ Age category } \\
\hline & 6-9 months & $56(30.8)$ & $55(29.1)$ \\
\hline & 10-11 month & 38 (20.9) & $27(14.3)$ \\
\hline & 12-24 months & $80(44.0)$ & $82(43.4)$ \\
\hline & 25-59 months & $8(4.3)$ & $25(13.2)$ \\
\hline \multicolumn{4}{|c|}{ Mother's educational status } \\
\hline & Uneducated & $25(14.0)$ & $12(6.5)$ \\
\hline & Educated & $154(86.0)$ & $174(93.5)$ \\
\hline \multicolumn{4}{|c|}{$\begin{array}{l}\text { Mother's level of education } \\
\text { (educated mothers) }\end{array}$} \\
\hline & Basic & $112(72.7)$ & $93(53.4)$ \\
\hline & Post-basic & $42(27.3)$ & $81(46.6)$ \\
\hline \multicolumn{4}{|c|}{ Mother's occupational status } \\
\hline & Unemployed & $33(18.1)$ & $15(7.9)$ \\
\hline & Employed & $149(81.9)$ & $174(92.1)$ \\
\hline \multicolumn{4}{|c|}{ Monthly family income } \\
\hline & $\leq 200 \mathrm{GH}$ Cedis $^{1}$ & $67(36.8)$ & $23(12.2)$ \\
\hline & >200 GH Cedis ${ }^{1}$ & $115(63.2)$ & $166(87.8)$ \\
\hline
\end{tabular}

${ }^{1} 1.00 \$=2.00 \mathrm{GH}$ Cedis

Family income levels were $>200 \mathrm{GH}$ Cedis in $63.2 \%(n=$ $115)$ and $87.8 \%(n=166)$ in malnourished and wellnourished children respectively.

Table 2 provides a description of the health outcomes of the study participants. A vast majority of the study participants recruited were out-patients comprising $72 \%$ of the malnourished group and $90.5 \%$ of the well-nourished group. There were four (4) cases of Kwashiorkor (oedematous SAM). Low birth weight was recorded in $13.9 \%(n=23)$ and $5.9 \%(n=10)$ of malnourished and well-nourished children respectively with developmental delay present in $15.9 \%(n=29)$ of malnourished children.

Table 3 is a description of uptake of interventions of the study participants. Inadequate number of antenatal visits $(20.9 \%, n=38)$ and postnatal visits of less than two $(27.5 \%, n=50)$ were reported in mothers of malnourished children. Only $6.6 \%(n=12)$ of malnourished children were de-wormed in the last six months compared with $20.6 \%(n=39)$ of well-nourished children. Assessment of the child health record booklet indicated that faltering growth had occurred in $77.2 \%(n=71$ and $19.5 \%(n=24)$ of malnourished and well-nourished 
Table 2 Health outcomes of 371 children attending PML hospital in Accra, Ghana

\begin{tabular}{|c|c|c|}
\hline \multirow[t]{2}{*}{ Characteristic } & \multicolumn{2}{|c|}{ Nutritional status of child } \\
\hline & $\begin{array}{l}\text { Malnourished } \\
\mathrm{n}, \%\end{array}$ & $\begin{array}{l}\text { Well-nourished } \\
\mathrm{n}, \%\end{array}$ \\
\hline \multicolumn{3}{|l|}{ Admission status } \\
\hline In-patient & $51(28.0)$ & $18(9.5)$ \\
\hline Out-patient & $131(72.0)$ & $171(90.5)$ \\
\hline \multicolumn{3}{|l|}{ Birth weight } \\
\hline Low $(<2.5$ kg) & $23(13.9)$ & $10(5.9)$ \\
\hline Normal ( $\geq 2.5$ kg) & $142(86.1)$ & $159(94.1)$ \\
\hline \multicolumn{3}{|c|}{$\begin{array}{l}\text { An episode of diarrhoea } \\
\text { (within last } 6 \text { months) }\end{array}$} \\
\hline Yes & $122(67.0)$ & $76(40.2)$ \\
\hline No & $60(33.0)$ & $113(59.8)$ \\
\hline \multicolumn{3}{|l|}{ Developmental delay } \\
\hline Yes & $29(15.9)$ & $3(1.6)$ \\
\hline No & $153(84.1)$ & $186(98.4)$ \\
\hline \multicolumn{3}{|l|}{$\begin{array}{l}\text { Hospital admission } \\
\text { (in the past one year) }\end{array}$} \\
\hline Yes & $82(45.1)$ & $46(24.3)$ \\
\hline No & $100(54.9)$ & $143(75.7)$ \\
\hline \multicolumn{3}{|c|}{$\begin{array}{l}\text { Passage of worm status } \\
\text { (in last } 6 \text { months) }\end{array}$} \\
\hline Passed worm & $6(3.3)$ & $3(1.6)$ \\
\hline No worm passed & $176(96.7)$ & $186(98.4)$ \\
\hline \multicolumn{3}{|c|}{ Sickness episode (in past 1 month) } \\
\hline Yes & $110(60.4)$ & $104(55.0)$ \\
\hline No & $72(39.6)$ & $85(45.0)$ \\
\hline
\end{tabular}

children respectively (Table 3 ). The proportion of mothers who had received breastfeeding and nutritional counselling was high in both study groups (93.4 \% in malnourished group and $99.5 \%$ in well-nourished group) (Table 3). Whereas the delivery room was reported as the commonest setting for nutritional counselling by mothers of malnourished children $(39.3 \%, n=57)$, the child health record book was reported as the commonest source by mothers of well-nourished children $(35.4 \%, n=62)$. The uptake of BCG vaccines was high (99.4\%) in both the malnourished group and the well-nourished group. The pentavalent vaccine was taken by $97.1 \%(n=167)$ of the malnourished children and $98.2 \%(n=164)$ of the well-nourished children (Table 3).

\section{Socio-economic and demographic factors associated with} malnutrition

Table 4 shows the socio-economic and demographic factors associated with malnutrition in the study participants. Gender, mother's educational status and mother's occupational status were not associated with malnutrition in the
Table 3 Uptake of interventions of 371 children and their mother's (caregivers) attending PML hospital in Accra, Ghana

\begin{tabular}{|c|c|c|c|}
\hline \multirow[t]{2}{*}{ Characteristic } & & \multicolumn{2}{|c|}{ Nutritional status of child } \\
\hline & & $\begin{array}{l}\text { Malnourished } \\
\mathrm{n}, \%\end{array}$ & $\begin{array}{l}\text { Well-nourished } \\
\mathrm{n}, \%\end{array}$ \\
\hline \multicolumn{4}{|c|}{ Number of antenatal visits } \\
\hline & Inadequate & $38(20.9)$ & $10(5.3)$ \\
\hline & Adequate & $144(79.1)$ & $179(94.7)$ \\
\hline \multicolumn{4}{|c|}{ Number of postnatal visits } \\
\hline & $<$ Two visits & $50(27.5)$ & $24(12.7)$ \\
\hline & $\geq$ Two visits & $132(72.5)$ & $165(87.3)$ \\
\hline \multicolumn{4}{|c|}{ De-worming status (in last 6 months) } \\
\hline & Not de-wormed & $170(93.4)$ & $150(79.4)$ \\
\hline & De-wormed & $12(6.6)$ & $39(20.6)$ \\
\hline \multicolumn{4}{|c|}{$\begin{array}{l}\text { Mother received breastfeeding } \\
\text { and nutritional counselling }\end{array}$} \\
\hline & No & $12(6.6)$ & $1(0.5)$ \\
\hline & Yes & $170(93.4)$ & $188(99.5)$ \\
\hline \multicolumn{4}{|c|}{ Growth monitoring indicator status } \\
\hline & Faltering & $71(77.2)$ & $24(19.5)$ \\
\hline & Growing well & $21(22.8)$ & $99(80.5)$ \\
\hline \multicolumn{4}{|l|}{ BCG vaccine } \\
\hline & No & $1(0.6)$ & $1(0.6)$ \\
\hline & Yes & $171(99.4)$ & $166(99.4)$ \\
\hline \multicolumn{4}{|c|}{ Penta-3 vaccine } \\
\hline & No & $5(2.9)$ & $3(1.8)$ \\
\hline & Yes & $167(97.1)$ & $164(98.2)$ \\
\hline \multicolumn{4}{|c|}{ Measles vaccine } \\
\hline & No & $22(15.0)$ & $14(9.9)$ \\
\hline & Yes & $125(85.0)$ & $128(90.1)$ \\
\hline \multicolumn{4}{|c|}{ Vitamin A status } \\
\hline & Not up to date & $44(25.6)$ & $39(23.4)$ \\
\hline & Up to date & $128(74.4)$ & $128(76.6)$ \\
\hline
\end{tabular}

multivariate analysis $(p>0.05)$ (Table 4$)$. Children who were 24 months and below had higher odds of being malnourished compared with those of 25-59 months (Adjusted $\mathrm{OR}=4.13$ [95 \% CI, 1.64-10.40], $p=0.003$ ). Similarly, family income levels of $\leq 200 \mathrm{GH}$ Cedis was associated with higher odds of malnutrition compared with income levels of $>200 \mathrm{GH}$ Cedis (Adjusted OR $=$ 4.23 [95\% CI, 2.41-7.44], $p<0.001$ ).

\section{Heath outcomes associated with malnutrition}

Table 5 shows the health outcomes associated with the uptake of interventions. In the multivariate analysis, children who had low birth weight (Adjusted OR, 2.65 [95 \% CI, 1.09-6.45], $p=0.032$ ) or showed evidence of developmental delay (Adjusted OR, 12.09 [95 \% CI, 2.68-54.57], $p=$ 
Table 4 Socio-economic and demographic factors associated with malnutrition in 371 children attending PML hospital in Accra, Ghana

\begin{tabular}{|c|c|c|c|c|c|}
\hline Characteristic & & Crude OR [95 \% Cl] & $p$-value & Adjusted OR $[95 \% \mathrm{CI}]^{2}$ & $p$-value \\
\hline \multicolumn{6}{|l|}{ Gender } \\
\hline & Female & $1.23[0.80-1.88]$ & 0.323 & - & - \\
\hline & Male & 1.00 & & & \\
\hline \multicolumn{6}{|l|}{ Age category } \\
\hline & $\leq 24$ months & $3.32[1.40-8.73]$ & 0.003 & $4.13[1.64-10.40]$ & 0.003 \\
\hline & 25-59 months & 1.00 & & 1.00 & \\
\hline \multicolumn{6}{|c|}{ Mother's educational status } \\
\hline & Uneducated & $2.35[1.09-5.31]$ & 0.017 & $2.06[0.95-4.47]$ & 0.067 \\
\hline & Educated & 1.00 & & 1.00 & \\
\hline \multicolumn{6}{|c|}{ Mother's occupational status } \\
\hline & Unemployed & $2.57[1.29-5.28]$ & 0.003 & $1.93[0.97-3.84]$ & 0.061 \\
\hline & Employed & 1.00 & & 1.00 & \\
\hline \multicolumn{6}{|c|}{ Monthly family income } \\
\hline & $\leq 200$ GH Cedis $^{1}$ & $4.20[2.41-7.48]$ & $<0.001$ & $4.23[2.41-7.44]$ & $<0.001$ \\
\hline & >200 GH Cedis ${ }^{1}$ & 1.00 & & 1.00 & \\
\hline
\end{tabular}

0.001) were associated with higher odds of malnutrition (Table 5). Similarly, children with an episode of diarrhoea (within the last 6 months) had a higher odds of malnutrition (Adjusted OR, 2.23 [95 \% CI, 1.36-3.66], $p=0.002$ ).

\section{Uptake of interventions to prevent malnutrition}

Table 6 shows the uptake of reproductive health and child health interventions that prevent malnutrition including antenatal and postnatal care, de-worming, breastfeeding and nutrition counselling, growth monitoring and immunisation. In the multivariate analysis, the inadequate or lack of antenatal visits was marginally associated with malnutrition (Adjusted OR, 4.31 [95 \% CI, 1.01-19.12], $p=0.049)$, whereas the number of postnatal visits was not $(p>0.05)$. The odds of being malnourished was 8.47 times higher in children who had not been de-wormed (in the last six months) compared with children had been de-wormed (Adjusted OR, 8.47 [95 \% CI, 1.99-36.01], $p=0.004$ ) (Table 6). Faltering growth recorded during growth monitoring was also associated with an increased odds of a child being malnourished (Adjusted OR, 21.40 [95 \% CI, 8.7452.41], $p<0.001$ ) in the multivariate analysis (Table 6). There was no significant difference between the uptake of the three immunisation vaccines or Vitamin A by children who were malnourished and those who were well-nourished $(p>0.05)$ (Table 6).

A total of 80 of the children have had one episode of diarrhoea comprising $26.4 \%$ of malnourished children and $16.9 \%$ of well-nourished children. Two or more episodes of diarrhoea were reported by $40.7 \%$ of the cases and $23.3 \%$ of the controls. Eleven malnourished children
(6.0\%) had 4 or more episodes of diarrhoea compared with $2.1 \%(n=4)$ of the well-nourished children.

\section{Discussion}

\section{Socio-economic and demographic factors}

In this study more than half of the malnourished children were in the 6 months to 12 months age group (Table 1). Since this coincides with the weaning period, it may well be that inappropriate weaning or complementary feeding practices may have been a major contributor to this finding $[3,14]$. A similar pattern was found in a study of admissions of children under the age of five years with protein energy malnutrition in Enugu, Nigeria [23]. The study on malnutrition at PML in the 1990 's differs in methodology from our study as the researchers specifically targeted children between 8 and 36 months. The average age then was around 14 months for underweight and 17 months for severe malnutrition [6].

We found that an age of 24 months or less was associated with malnutrition in the multivariate analysis. It is well known that this age group is most vulnerable to malnutrition and its effects [24]. At the same time the age group provides a window of opportunity for intervening to reduce the effects of malnutrition hence the emergence of the Scaling Up Nutrition (SUN) movement which aims at mitigating nutritional problems during pregnancy, and in this age group [24, 25]. It is a country-led process which brings organizations together to support nations to implement nutrition interventions in their national plans through multidisciplinary working.

A monthly family income of $\leq 200 \mathrm{GH}$ Cedis ( $\leq 100$ USD) was associated with malnutrition in the multivariate 
Table 5 Health outcomes associated with malnutrition in 371 children attending PML hospital in Accra, Ghana

\begin{tabular}{|c|c|c|c|c|c|}
\hline Characteristic & & Crude OR [95 \% Cl] & $p$-value & Adjusted OR $[95 \% \text { CI] }]^{2}$ & $p$-value \\
\hline \multicolumn{6}{|l|}{ Age category } \\
\hline & $\leq 24$ months & $3.32[1.40-8.73]$ & 0.003 & $4.65[1.73-12.55]$ & 0.002 \\
\hline & 25-59 months & 1.00 & & 1.00 & \\
\hline \multicolumn{6}{|c|}{ Monthly family income } \\
\hline & $\leq 200$ GH Cedis $^{1}$ & $4.20[2.41-7.48]$ & $<0.001$ & $2.93[1.59-5.42]$ & 0.001 \\
\hline & $>200 \mathrm{GH}$ Cedis $^{1}$ & 1.00 & & 1.00 & \\
\hline \multicolumn{6}{|c|}{ Admission status } \\
\hline & In-patient & $3.70[2.01-7.04]$ & $<0.001$ & $2.10[0.98-4.50]$ & 0.057 \\
\hline & Out-patient & 1.00 & & 1.00 & \\
\hline \multicolumn{6}{|l|}{ Birth weight } \\
\hline & $\operatorname{Low}(<2.5 \mathrm{~kg})$ & $2.58[1.13-6.26]$ & 0.014 & $2.65[1.09-6.45]$ & 0.032 \\
\hline & Normal $(\geq 2.5 \mathrm{~kg})$ & 1.00 & & 1.00 & \\
\hline \multicolumn{6}{|c|}{ An episode of diarrhoea (within last 6 months) } \\
\hline & Yes & $3.02[1.94-4.73]$ & $<0.001$ & $2.23[1.36-3.66]$ & 0.002 \\
\hline & No & 1.00 & & 1.00 & \\
\hline \multicolumn{6}{|c|}{ Developmental delay } \\
\hline & Yes & $11.75[3.52-61.11]$ & $<0.001$ & $12.09[2.68-54.57]$ & 0.001 \\
\hline & No & 1.00 & & 1.00 & \\
\hline \multicolumn{6}{|c|}{ Hospital admission (in the past one year) } \\
\hline & Yes & $2.55[1.60-4.07]$ & $<0.001$ & $1.70[0.93-3.10]$ & 0.086 \\
\hline & No & 1.00 & & 1.00 & \\
\hline \multicolumn{6}{|c|}{ Passage of worm status in last 6 months } \\
\hline & Passed worm & $2.11[0.44-13.23]$ & 0.285 & - & - \\
\hline & No worm passage & 1.00 & & & \\
\hline \multicolumn{6}{|c|}{ Sickness episode (in past 1 month) } \\
\hline & Yes & $1.25[0.81-1.93]$ & 0.291 & - & - \\
\hline & No & 1.00 & & & \\
\hline
\end{tabular}

${ }^{1} 1.00 \$=2.00 \mathrm{GH}$ Cedis; ${ }^{2}$ Varibales with $p<0.2$ in the univariate analysis were entered into the multivariate analysis model in addition to age category and family income level; $\mathrm{OR}=$ Odds ratio; $\mathrm{Cl}=$ Confidence interval

analysis reiterating the importance of poverty in the aetiology of malnutrition in this setting [26]. This is similar to a previous study in Ghana which found that economic inequality is strongly associated with chronic under - nutrition. It is also similar to a study in Nigeria which found that maternal monthly income $<\$ 20$, monthly household food expenditure of $<\$ 55$ was associated with malnutrition [26]. In contrast, the educational status of mothers and their occupational status in this study were only significantly associated with malnutrition in the univariate analysis and not in the multivariate analysis. The researchers in Nigeria also found that malnutrition was significantly. associated with education below secondary level in a univariate but not in multivariate analysis of its determinants [27]. They also found that residence in a one room apartment, higher birth order and incomplete immunization of the child were significantly associated with malnutrition in that study consequently, they suggested a multidisciplinary approach for preventive strategies just as the SUN movement has done [27]. We did not find an association between immunisation status and malnutrition possibly because immunisation rates were similar in both groups and was high. It could be that making a health service such as immunisations readily accessible reduces the effects of poverty and health inequalities.

Although poverty can exert its influence on all three arms of the UNICEF conceptual frame work of underlying causes of malnutrition, it has a major effect on household food security [28]. Food security is determined by several factors including food prices, agricultural practices, climate change and market forces among others [29]. There was a gradual increase in the number of people worldwide who were underweight from 1990, peaking in 2008. This was worsened by the global recession in 2008 and 2009 which particularly affected the 
Table 6 Uptake of interventions associated with malnutrition in 371 children attending PML hospital in Accra, Ghana

\begin{tabular}{|c|c|c|c|c|c|}
\hline Characteristic & & Crude OR [95 \% Cl] & $p$-value & Adjusted OR $[95 \% \mathrm{CI}]^{2}$ & $p$-value \\
\hline \multicolumn{6}{|l|}{ Age category } \\
\hline & $\leq 24$ months & $3.32[1.40-8.73]$ & 0.003 & $1.90[0.38-9.48]$ & 0.431 \\
\hline & 25-59 months & 1.00 & & 1.00 & \\
\hline \multicolumn{6}{|c|}{ Monthly family income } \\
\hline & $\leq 200$ GH Cedis ${ }^{1}$ & $4.20[2.41-7.48]$ & $<0.001$ & $1.98[0.65-6.01]$ & 0.229 \\
\hline & >200 GH Cedis ${ }^{1}$ & 1.00 & & 1.00 & \\
\hline \multicolumn{6}{|c|}{ Number of antenatal visits } \\
\hline & Inadequate/none & $4.72[2.21-10.96]$ & $<0.001$ & $4.31[1.01-19.12]$ & 0.049 \\
\hline & Adequate & 1.00 & & 1.00 & \\
\hline \multicolumn{6}{|c|}{ Number of postnatal visits } \\
\hline & $<$ Two visits & $2.60[1.48-4.67]$ & $<0.001$ & $0.84[0.27-2.55]$ & 0.753 \\
\hline & $\geq$ Two visits & 1.00 & & 1.00 & \\
\hline \multicolumn{6}{|c|}{ De-worming status (in last 6 months) } \\
\hline & Not de-wormed & $3.68[1.80-8.00]$ & $<0.001$ & $8.47[1.99-36.01]$ & 0.004 \\
\hline & De-wormed & 1.00 & & 1.00 & \\
\hline \multicolumn{6}{|c|}{ Received breastfeeding/nutritional counselling } \\
\hline & No & $13.27[1.92-570.13]$ & 0.002 & Not estimable ${ }^{3}$ & Not estimable \\
\hline & Yes & 1.00 & & & \\
\hline \multicolumn{6}{|c|}{ Growth monitoring indicator status } \\
\hline & Faltering & $13.95[6.87-28.56]$ & $<0.001$ & $21.40[8.74-52.41]$ & $<0.001$ \\
\hline & Growing well & 1.00 & & 1.00 & \\
\hline \multicolumn{6}{|l|}{ BCG vaccine } \\
\hline & No & $0.97[0.01-76.65]$ & 0.983 & - & - \\
\hline & Yes & 1.00 & & & \\
\hline \multicolumn{6}{|c|}{ Penta-3 vaccine } \\
\hline & No & $1.64[0.31-10.69]$ & 0.501 & - & - \\
\hline & Yes & 1.00 & & & \\
\hline \multicolumn{6}{|c|}{ Measles vaccine } \\
\hline & No & $1.61[0.75-3.56]$ & 0.189 & $0.56[0.15-2.02]$ & 0.373 \\
\hline & Yes & 1.00 & & 1.00 & \\
\hline \multicolumn{6}{|c|}{ Vitamin A status } \\
\hline & Not up to date & $1.13[0.67-1.91]$ & 0.633 & - & - \\
\hline & Up to date & 1.00 & & & \\
\hline
\end{tabular}

\footnotetext{
${ }^{1} 1.00 \$=2.00 \mathrm{GH}$ Cedis; ${ }^{2}$ Varibales with $p<0.2$ in the univariate analysis were entered into the multivariate analysis model in addition to age category and family
} income level; ${ }^{3}$ Not estimable due to coll inearity; $\mathrm{OR}=$ Odds ratio; $\mathrm{Cl}=$ Confidence interval

urban poor. It led to price hikes in food, limiting food consumption and causing a shift to less balanced diets. It also left less resources for buying goods and services to ensure hygienic practices, health and well being [29]. Suggestions have been made to counteract this by promoting agricultural growth, measures to reduce extreme market volatility, and expansion of social protection and child nutrition action particularly nutrition sensitive interventions [29-31].

In response to this call, there have been several studies exploring the use of social protection measures such as cash transfers to mitigate the effects of poverty on malnutrition in childhood and some have been particularly successful as reported in a study in Niger [32]. This study found that preventive distributions of supplementary food and cash transfer were better at preventing MAM and SAM than either of these measures alone. However, it is not clear how this can be sustained in the long term. In any case it is rewarding to note that there are plans to ensure that strong social protection measures are enshrined in the upcoming sustainable development goals. 


\section{Health outcomes}

The results of the study showed that low birth weight, having an episode of diarrhoea within the last 6 months and the presence of developmental delay were all associated with malnutrition in the multivariate analysis. Similar findings have been reported by other studies [3, 6, 23]. On the other hand, although having been admitted to hospital within the past one year was associated with malnutrition in the univariate analysis, the association was not statistically significant in the multivariate analysis. There was also no relationship between sickness episodes and malnutrition unlike the study by Maleta et al. [33] in Malawi which found that malnutrition was associated with frequent illness episodes in infancy. It is possible that we may have found an association if we had focussed on infancy as they did.

Diarrhoeal diseases are generally more frequent and tend to be more severe in malnourished children because of the association between malnutrition and infection [1-3]. In this study, $40.7 \%$ of the malnourished children had two or more episodes of diarrhoea compared to $23.3 \%$ of the controls. This suggests that efforts to control diarrhoea are important for effective prevention of malnutrition. This must include providing effective advice on feeding during diarrhoea episodes and adequate follow up after each episode. It is also important that protocols exist for investigating and managing children who have relapsed after previous treatment for diarrhoea to exclude underlying medical conditions [23]. Developmental delay was more prevalent in malnourished children and associated with increased odds of being malnourished. Malnutrition often causes developmental delay however malnutrition can also be precipitated in feeding difficulties due to a chronic neurological problem [9]. It appears this association was more of an effect rather than a cause of malnutrition in most of the children. However eight (8) out of the 29 malnourished children with developmental delay were reported to have had problems at birth and one (1) had a chronic neurological condition, cerebral palsy which could have precipitated the delay in data not presented here. Early intervention will ensure that these children make the most of their developmental potential to reduce the effect of malnutrition [30, 34, 35].

\section{Uptake of interventions}

The study found that inadequate/lack of antenatal care was associated with malnutrition in the multivariate analysis although the association was marginal. This implies that mothers of malnourished children were less likely to have had adequate health contacts through antenatal visits. The present result is similar to a study in three Latin American countries which found only a weak association between antenatal care and reduction in the level of child malnutrition and some variations between countries
[10]. They attributed these findings to differences in the quality of care and health inequalities.

Antenatal care provides opportunities for nutritional counselling which mothers of well nourished children may have benefited from and it has been shown to be effective if there is food security [11, 13, 14]. It is also worthy to note that the mothers of malnourished children reported the delivery room to be the main setting for nutritional counselling, whereas mothers of well nourished children reported the child health record books as their main source of nutritional advice. The study also shows that mothers of well nourished children were more likely to de-worm their children every 6 months. Regular deworming of children has been reported to be a useful intervention for preventing malnutrition in some settings and this appears to be one $[11,14]$. Furthermore, a majority of the mothers reported that they had nutritional counselling or advise from the health service which is one of the interventions expected in a national plan $[16,17,24]$. The delivery room is an important setting for counselling mothers on early initiation of breast feeding [36].

Since maternity care is free in all government health institutions, pregnant women should be encouraged to access antenatal care and the health serivice should engage those mothers who miss out through home visiting. However a more specific and targeted approach will be needed. Vitamin A supplementation was not associated with malnutrition even in the univariate analysis. Although Vitamin A reduces child mortality, it is not known to affect anthropometric measurements [14].

Growth faltering occurred in both groups; however it was significantly more common in children with malnutrition and was still significant after multivariate analysis. This is not an unexpected finding. We encountered some incomplete records which are most likely because most mothers come for growth monitoring only when their child's immunisations are due. They used to stop at 9 months after the measles immunisation but more recently this has gone up to 18 months since the second dose of measles was introduced. Additional clinic visits may be necessary to pick up and monitor children who are faltering between the ages of 9 and 18 months and above. The usefulness of these visits needs to be established first since growth monitoring has been used in several intervention programmes with mixed results $[11,14]$.

The main limitation of this study was a challenge related to the classification of malnutrition. Weight for height criteria was used to make the results comparable to other studies. The WHO recommends the use of both MUAC and weight for height as independent criteria for classifying malnutrition whereas nutrition rehabilitation centres in Ghana including PML use only MUAC [20]. We found that about a third of patients who would have passed as being well-nourished using MUAC criteria 
could not be included in the control group because they were malnourished using weight-for-height criteria. This means that there may be several malnourished children who are missed each day. Missed opportunities for picking up malnourished children has been reported in several studies, including a study in a teaching hospital in Ghana [37-39]. Understandably, MUAC is an easier and more practical measurement in small peripheral health facilities. However, in larger health facilities like PML and teaching hospitals, it should be possible to do weight and height measurements routinely and hence record weight for height measurements. Further studies are needed to assess the effect of using either criteria on the prevalence and cost-benefit of management as it may well be that the burden of malnutrition in the hospital is much higher than we are treating.

Children with Kwashiorkor who could not stand to have their heights measured or were too ill were not included. There was a slight over representation of older children among the well nourished children. Also the patients were not matched so it is possible that this may have created a bias. We also recognise that children labelled as well-nourished are likely to contain some children with mild malnutrition; however, for the purposes of this study, we have classified them as controls in line with current classification of malnutrition.

\section{Conclusions}

Malnutrition was associated with a monthly family income of $\leq 200$ GH Cedis ( $\leq 100$ USD) but not with maternal educational status and employment status which highlights a need to address poverty. Malnutrition was also associated with lack or inadequate antenatal care, not de-worming children regularly, low birth weight, previous diarrhoea episodes, and developmental delay. Though the latter three conditions could be consequences of malnutrition they could aggravate malnutrition through lack of health services. Thus preventing these conditions and providing adequate follow up for diarrhoea patients will be important steps in preventing malnutrition in this population. Interventions to reduce malnutrition were generally better patronised by the mothers of well nourished children. Efforts must be made to reach mothers who default on antenatal visits and de-worming their children regularly. Furthermore, growth monitoring should be encouraged in this setting and further studies on the timing and use of information from the activity are needed.

\section{Abbreviations \\ MAM: Moderate acute malnutrition; MUAC: Mid - upper arm circumference; SAM: Severe acute malnutrition; PML: Princess Marie Louise Children's Hospital.}

\section{Competing interests}

The authors declare that they have no competing interests.

\section{Authors' contribution}

The authors EMAT, EKS and ETN worked in the conception, study design, and the final article composition. EMAT, ETN and EKS contributed to the methods. ETN and EMAT worked on the data analysis, results, discussion, conclusion and its continuous critical review. All the authors read and approved the final manuscript.

\section{Acknowledgments}

Peter Nuro-Ameyaw, Samson Dziekpor, Priscilla Tete-Donkor and Hannah Ofori assisted in the data collection and entry. Professor Richard Biritwum assisted in editing and research advice. ORID of the University of Ghana funded the study.

\section{Author details}

${ }^{1}$ Department of Community Health, School of Public Health, University of Ghana, P.O. Box 4236, Accra, Ghana. ²Princess Marie Louis Children's Hospital (PML), P.O. Box GP 122, Accra, Ghana. ${ }^{3}$ World Health Organisation Collaborating Centre for Advocacy and Training in Pharmacovigilance, Centre for Tropical Clinical Pharmacology \& Therapeutics, School of Medicine and Dentistry, University of Ghana, P. O. Box GP 4236, Accra, Ghana.

Received: 30 April 2015 Accepted: 23 October 2015

Published online: 19 November 2015

\section{References}

1. Muller $\mathrm{O}$, Krawinkel M. Malnutrition and health in developing countries. CMAJ. 2005;173(3):279-86.

2. Black RE, Morris SS, Bryce J. Where and why are 10 million children dying every year? Lancet. 2003;361(9376):2226-34.

3. Black RE, Allen LH, Bhutta ZA, Caulfield LE, de Onis M, Ezzati M, et al. Maternal and child undernutrition: global and regional exposures and health consequences. Lancet. 2008;371(9608):243-60.

4. Caulfield LE, de Onis M, Blossner M, Black RE. Undernutrition as an underlying cause of child deaths associated with diarrhea, pneumonia, malaria, and measles. Am J Clin Nutr. 2004;80(1):193-8.

5. UNICEF, WHO. Estimates TWBJCM: Levels \& Trends in Child Malnutrition, vol. 2015. Geneva: WHO; 2013.

6. Rikimaru T, Yartey JE, Taniguchi K, Kennedy DO, Nkrumah FK. Risk factors for the prevalence of malnutrition among urban children in Ghana. J Nutr Sci Vitaminol (Tokyo). 1998;44(3):391-407.

7. Ighogboja SI. Some factors contributing to protein-energy malnutrition in the middle belt of Nigeria. East Afr Med J. 1992;69(10):566-71.

8. Tomkins A, Watson F: Malnutrition and Infection; A review. In: UN ACC/SCN. vol. Nutrition policy discussion paper. Geneva: Administrative committee on coordination-subcommittee on nutrition; 1989. http://www.unscn.org/ layout/modules/resources/files/Policy_paper_No_5.pdf.

9. Grantham-McGregor S, Cheung YB, Cueto S, Glewwe P, Richter L, Strupp B. Developmental potential in the first 5 years for children in developing countries. Lancet. 2007;369(9555):60-70.

10. Forero-Ramirez N, Gamboa LF, Bedi A, Sparrow R. Child malnutrition and prenatal care: evidence from three Latin American countries. Revista panamericana de salud publica =Pan American journal of public health. 2014;35(3):163-71.

11. Bhutta ZA, Das JK, Rizvi A, Gaffey MF, Walker N, Horton S, et al. Evidencebased interventions for improvement of maternal and child nutrition: what can be done and at what cost? Lancet. 2013;382(9890):452-77.

12. GHS. Annual Report of the Reproductive and Child Health and Family Health Division. Accra: Ghana Health Service; 2007.

13. Lartey A. Maternal and child nutrition in Sub-Saharan Africa: challenges and interventions. Proc Nutr Soc. 2008;67(1):105-8.

14. Bhutta ZA, Ahmed T, Black RE, Cousens S, Dewey K, Giugliani E, et al. What works? Interventions for maternal and child undernutrition and survival. Lancet. 2008:371(9610):417-40.

15. Santosh Kumar A, Sunil Kumar D, Ashok NC, Ragavendraswamy Koppad R. Protein energy malnutrition and its association with immunization status and common morbidities among 1-5 year aged children in southern part of India, Mysore. Int J Curr Res Rev. 2013;5(2):105-10.

16. Brantuo MNA, Okwabi W, Adu-Afuawuah S, Agyepong E, Attafuah NT, Brew $G$, et al. Landscape analysis of readiness to accelerate the reduction of maternal and child undernutrition in Ghana. SCN News. 2009;37(1564-3743):31-7. 
17. Ghana Health Service: Child Health Policy. MOH: Under Five's Child Health Policy 2007-2015. In. Accra: Ghana Health Service; 2008.

18. UNICEF: Underlying causes of undernutrition: Food insecurity. Food insecurity In. Geneva: UNICEF.UNICEF: Underlying causes of undernutrition: Food insecurity. In. Geneva: UNICEF. http://www.unicef.org/nutrition/training/2.5/ 9.html.

19. GHS. Interim National Guidelines for Community-Based Management of Severe Acute Malnutrition in Ghana. Ghana: Ghana Health Service; 2010

20. WHO, UNICEF. WHO child growth standards and the identification of severe acute malnutrition in infants and children; A Joint Statement. Geneva: WHO; 2009.

21. Onis M, Blössner M. Global Database on Child Growth and Malnutrition. In: Programme of Nutrition. Geneva: WHO; 1997.

22. UNHCR: MUAC and WFH z-score as indicators of severe acute malnutrition: a consultation of operational agencies and academic specialists to understand the evidence, identify knowledge gaps and to inform operational guidance. In. Geneva: ENN; 2012. http://www.cmamforum.org/ Pool/Resources/MUACWFH-Report-ENN-2013.pdf.

23. Ubesie AC, Ibeziako NS, Ndiokwelu Cl, Uzoka CM, Nwafor CA. Under-five protein energy malnutrition admitted at the University of Nigeria Teaching Hospital, Enugu: a 10 year retrospective review. Nutr J. 2012;11:43.

24. Bryce J, Coitinho D, Darnton-Hill I, Pelletier D, Pinstrup-Andersen P. Maternal and child undernutrition: effective action at national level. Lancet. 2008:371(9611):510-26.

25. Scaling Up Nutrition: A Framework for Action [http://scalingupnutrition.org/ wp-content/uploads/2013/05/SUN_Framework.pdf].

26. Hong R. Effect of economic inequality on chronic childhood undernutrition in Ghana. Public Health Nutr. 2007;10(4):371-8.

27. Owoaje $E$, Onifade $\mathrm{O}$, Desmennu A. Family and socioeconomic risk factors for undernutrition among children aged 6 to 23 Months in Ibadan, Nigeria. Pan Afr Med J. 2014;17:161.

28. Bain LE, Awah PK, Geraldine N, Kindong NP, Sigal Y, Bernard N, et al. Malnutrition in Sub-Saharan Africa: burden, causes and prospects. Pan Afr Med J. 2013;15:120

29. von Braun J. Food insecurity, hunger and malnutrition: necessary policy and technology changes. N Biotechnol. 2010;27(5):449-52.

30. Ruel MT, Alderman H. Nutrition-sensitive interventions and programmes: how can they help to accelerate progress in improving maternal and child nutrition? Lancet. 2013;382(9891):536-51.

31. Mucha N. Preventing Moderate Acute Malnutrition (MAM) Through NutritionSensitive Interventions. In: CMAM Forum Technical Brief. 2014.

32. Langendorf $C$, Roederer $T$, de Pee S, Brown D, Doyon S, Mamaty AA, et al. Preventing acute malnutrition among young children in crises: a prospective intervention study in Niger. PLoS Med. 2014;11(9), e1001714.

33. Maleta K, Virtanen SM, Espo M, Kulmala T, Ashorn P. Childhood malnutrition and its predictors in rural Malawi. Paediatr Perinat Epidemiol. 2003;17(4):384-90.

34. Dreyer BP. Early childhood stimulation in the developing and developed world: if not now, when? Pediatrics. 2011;127(5):975.

35. Engle PL, Black MM, Behrman JR, Cabral de Mello M, Gertler PJ, Kapiriri L, et al. Strategies to avoid the loss of developmental potential in more than 200 million children in the developing world. Lancet. 2007;369(9557):229-42.

36. Crenshaw JT. Healthy birth practice \#6: keep mother and baby together- It's best for mother, baby, and breastfeeding. J Perinat Educ. 2014;23(4):211-7.

37. Aguayo VM, Roley JA, Malanzele J, Meershoek SP. Opportunities for improving the quality of nutritional services in the national health system in Mozambique: findings from Manica Province. J Trop Pediatr. 2004;50(5):314-8.

38. Hampshire RD, Aguayo VM, Harouna H, Roley JA, Tarini A, Baker SK. Delivery of nutrition services in health systems in sub-Saharan Africa: opportunities in Burkina Faso, Mozambique and Niger. Public Health Nutr. 2004;7(8):1047-53.

39. Antwi S. Malnutrition: missed opportunities for diagnosis. Ghana Med J. 2008:42(3):101-4

\section{Submit your next manuscript to BioMed Central and take full advantage of:}

- Convenient online submission

- Thorough peer review

- No space constraints or color figure charges

- Immediate publication on acceptance

- Inclusion in PubMed, CAS, Scopus and Google Scholar

- Research which is freely available for redistribution

Submit your manuscript at www.biomedcentral.com/submit 